\title{
ARTHROPATHY OF THE ANKLE IN CONGENITAL INDIFFERENCE TO PAIN
}

\author{
G. K. Rose, Shrewsbury, England \\ From the Robert Jones and Agnes Hunt Orthopaedic Hospital, Oswestry
}

A boy born in December 1947 came under the care of Mr A. M. Hendry and myself shortly before his second birthday. He had bow legs, which had been treated elsewhere with night splints, under which sores had appeared rather readily. Splinting was therefore abandoned and the sores healed, while the legs, with no treatment at all, gradually became straighter. Just before his third birthday he twisted his right ankle. The joint swelled, and radiographs taken one week after the injury showed well marked osteochondritis of the talus (Fig. 1).

He was admitted to hospital for treatment of the ankle. It was then noticed that he had a habit of biting lumps of skin out of his fingers and that his tongue was very scarred. He was quickly shown to be quite insensitive to pain. He could be lifted by his hair.

The consulting neurologist to the Robert Jones and Agnes Hunt Hospital, Dr G. E. Smyth, found no sign of any other abnormality in the nervous system. He drew our attention to Ford's (1952) classical account of congenital indifference to pain, and close questioning of the mother established that this child's defective sensation was, in fact, lifelong.

It was decided to immobilise the ankle in plaster and, after a period of such fixation without bearing weight, he was allowed to walk in the plaster and to return home. Three days later he was seen by an after-care sister, who found his toes pink and warm and all satisfactory. About midnight that night he awoke, oddly enough complaining of pain in his right leg. He spent a restless night and at daybreak his mother recognised that his toes were discoloured. When he was brought to the hospital six hours later it was immediately obvious that a circulatory catastrophe had occurred. The plaster was immediately removed, and as it was removed a small plastic toy fell out from between the plaster and the upper part of the calf. It was shaped like a large comma, and there was an area of compression of similar shape and size in the skin just over the line of the popliteal artery (Figs. 3 and 4). The leg below the knee was swollen, cold, pulseless and paralysed. The skin of the foot and of the lower part of the leg was blue-black and apparently gangrenous (Fig. 5). There was no circulatory return on pressing the skin of the toes. The boy was seen by Sir Reginald Watson-Jones and $\mathrm{Mr} \mathrm{D}$. Ll. Griffiths about four hours after removal of the plaster, by which time the circulation had improved a little and the skin was warmer below the knee. $\mathrm{Mr}$ Griffiths injected 10 cubic centimetres of 2 per cent procaine around the right lumbar :ympathetic cord. After about fifteen minutes the skin became warm down to the malleoli and a slow vascular return appeared on compressing the toes. Eventually a shallow skin slough separated from the dorsum of the foot and small areas of skin were lost from the tips of the four outer toes, but the lesions healed without skin grafting and without ischaemic contractures, though the toes were paralysed for nearly twelve weeks.

Since the vascular accident there has been evidence of increasing sensitivity to pain, but at the age of three years nine months he fractured his right clavicle without any pain. It united well. The ankle improved steadily in a weight-relieving caliper. Soon after his fourth birthday, when a hot-water bottle leaked he gave early warning of minor burns which resulted; but a few months later he developed a perforating ulcer of the right great toe. His sensitivity to pain is becoming progressively nearer to normal and he now feels the minor 


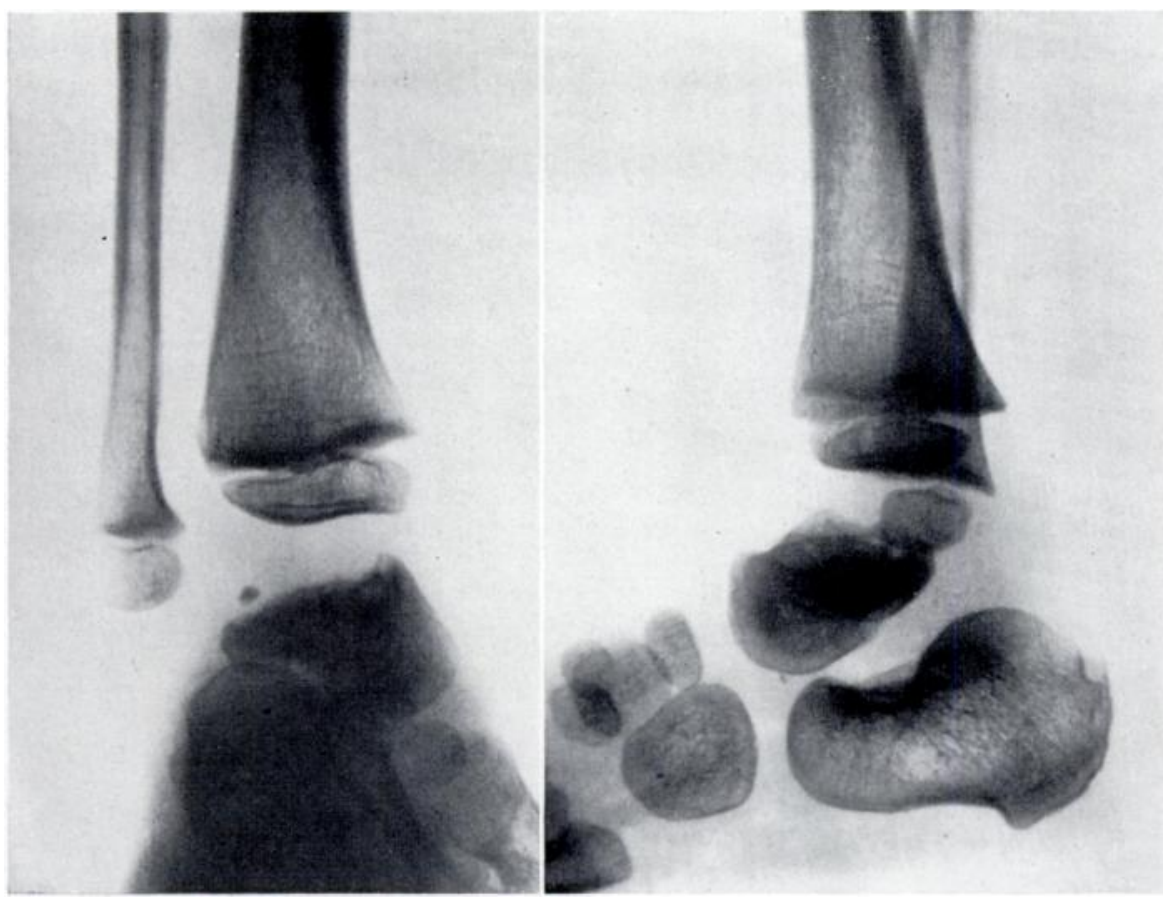

FIG. 1

Right ankle at the age of three years, showing well marked osteochondritis of the talus

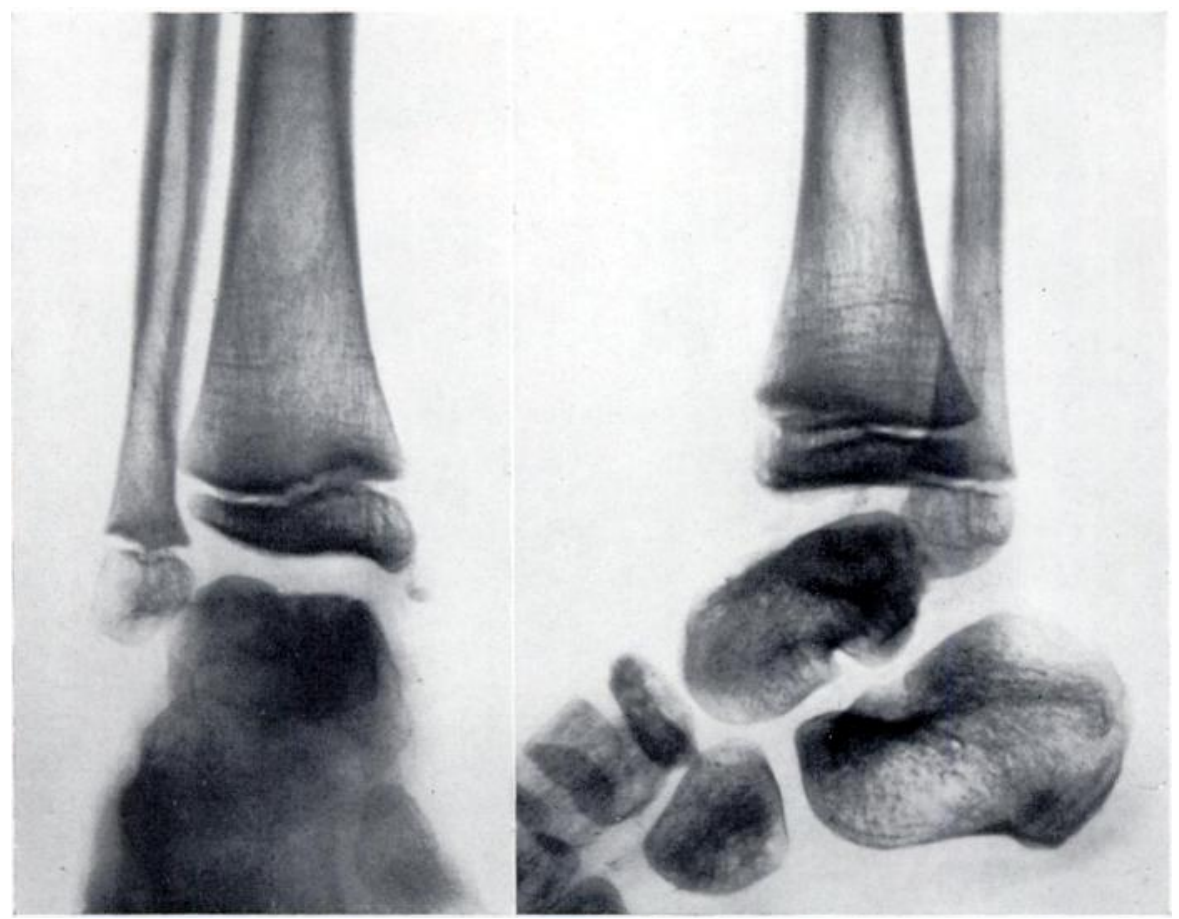

FIG. 2

Three years later, after incomplete return of sensitivity to pain.

vol. 35 B, No. 3, AUgust 1953 


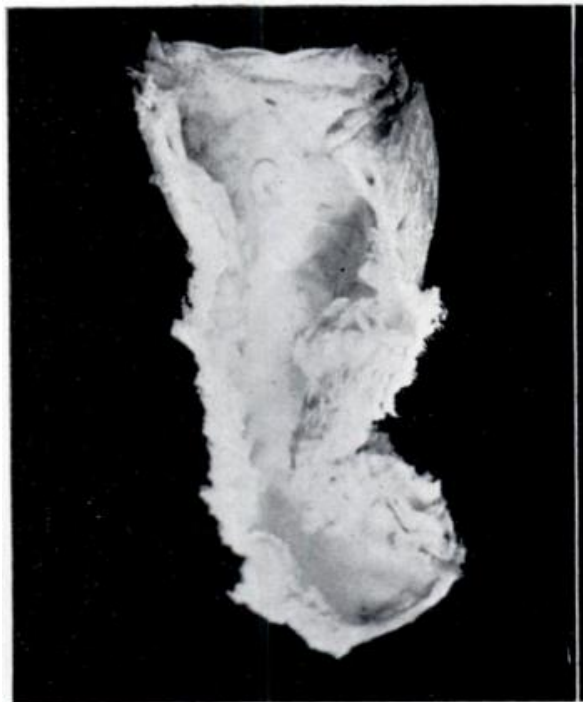

FIG. 3

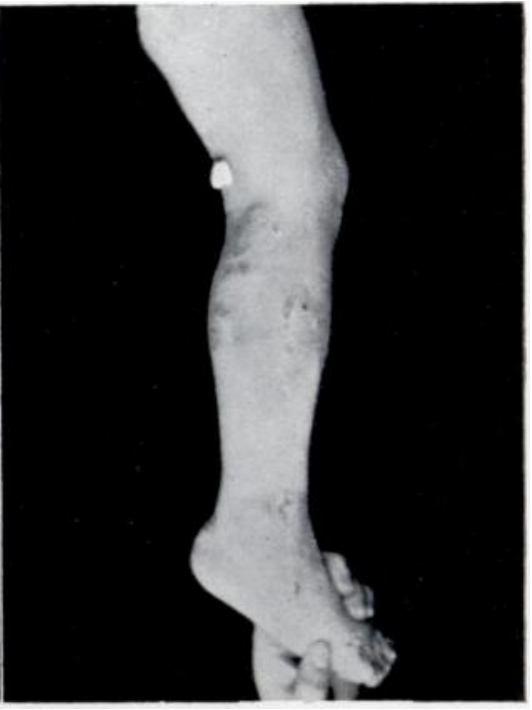

Fig. 4

The cause of the vascular accident - a plastic toy pushed inside the plaster. Figure 3 shows the tor embedded in the plaster case. Figure 4 shows the position of the tov in relation to the child's limb. (The critical state of the circulation is not shown clearly in the photograph.)

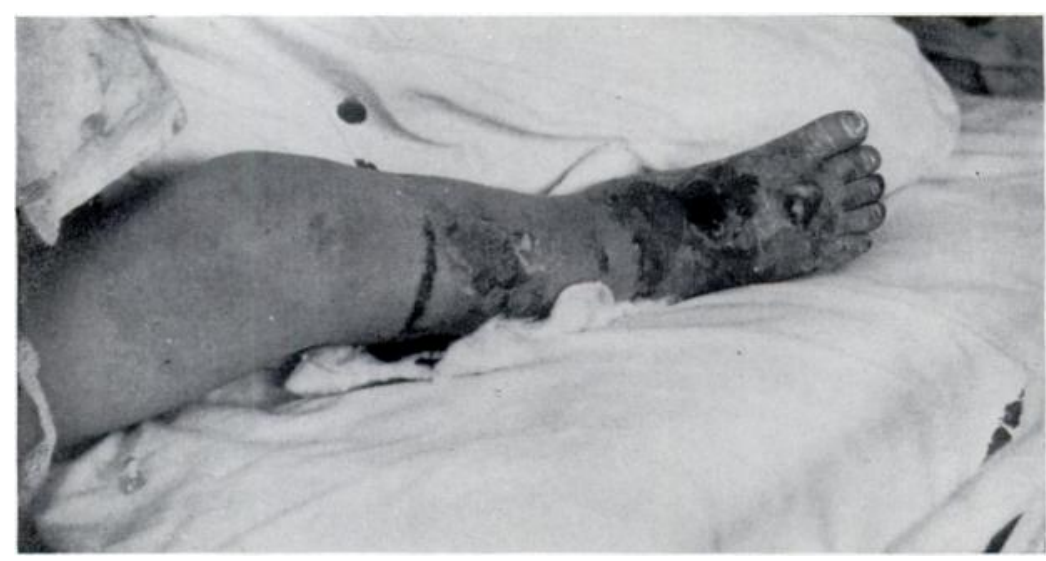

Flli. 5

Condition of leg ten days after removal of the plaster.

injuries of a boy's life as well as any other child. The condition of the ankle has meanwhile improved steadily. (Fig. 2).

\section{DISCUSSION}

The most interesting feature of this case was the improvement in the condition of the ankle as sensitivity to pain developed. It is hoped that further recovery will occur and that other complications will be avoided. We can only guess why he felt the pain of his circulatory block, but it is possible that deep pain sensation was sufficiently acquired by the time of that incident to enable him to appreciate the pain of severe ischaemia.

\section{REFERENCE}

FORI, F. R. (1952): Iiseases of the Nervous System in Infancy, Childhood and Adolescence. Third edition. () ford: Blackwell Scientific Publications. 